\title{
The evolving activities of the tobacco industry in the Eastern Mediterranean Region and response strategies ${ }^{1}$
}

Citation: The evolving activities of the tobacco industry in the Eastern Mediterranean Region and response strategies. East Mediterr Health J. 2020;26(10):1312-1313 https://doi.org/10.26719/2020.26.10.1312

Copyright (C) World Health Organization (WHO) 2020. Open Access. Some rights reserved. This work is available under the CC BY-NC-SA 3.0 IGO license (https://creativecommons.org/licenses/by-nc-sa/3.o/igo).

\section{Introduction}

In recent years, the tobacco industry has radically changed its operations and strategies in order to continue to influence tobacco control policy and further its interests in a world that increasingly views cigarettes in a negative light. It has promoted new products that it claims are less harmful than conventional cigarettes and pursued a "harm reduction" public relations strategy to influence public perception and policy-making. For many years, pursuing policy change has been the only tool used by Member States of the World Health Organization (WHO) Eastern Mediterranean Region to prevent tobacco industry interference. However, during the $66^{\text {th }}$ session of the Regional Committee for the Eastern Mediterranean in October 2019 (1), Member States requested WHO technical advice on exploring other strategies including litigation. Such litigation would not only aim for compensation from the tobacco industry, but for legislative enforcement and prevention of interference in general.

In light of the evolving strategies of the tobacco industry to subvert tobacco control efforts and the new challenges thus posed, the WHO Regional Office for the Eastern Mediterranean technically partnered with the American University in Beirut, Lebanon, to hold a consultative meeting on future implementation of Article 5.3 of the WHO Framework Convention on Tobacco Control (WHO FCTC) and to explore new strategies for ending tobacco industry interference, including litigation

(2) . The aims of the meeting were to:

- examine the scope and details of tobacco industry interference in the Region

- discuss how health advocates and governments should address the "harm reduction" claimed by the tobacco industry

- discuss suitable tools for responding to these new marketing strategies.

\section{Summary of discussion}

During the consultation, it was well documented that the tobacco industry is using similar marketing strategies for novel and emerging products to those used for traditional tobacco products, including: marketing to women and children; denying any negative health consequences; using health professionals to promote products; and using products as tools to promote the acceptability of tobacco use. In addition, tobacco companies are marketing novel and emerging nicotine and tobacco products such as heated tobacco products (HTPs) as "reduced risk" in order to create a new segment in the tobacco market and limit regulation. Tobacco companies are also engaged in the production and marketing of electronic nicotine delivery systems (ENDS). The tobacco industry often seeks to conflate products which do not contain tobacco, with HTPs. This serves to confuse governments in a context where WHO FCTC obligations apply to all tobacco products including HTPs, which the industry refers to as "smoke-free" products. In summary, and based on the Conference of the Parties (COP) decisions, HTPs are tobacco products to which all WHO Framework Convention on Tobacco Control (FCTC) (3) regulations apply. While electronic non-nicotine delivery systems (ENNDS) are not tobacco products, based on the suggested regulatory options of the COP, this consultation considered all possible options for regulating the activities of their associated industry.

\section{Recommendations}

\section{To WHO}

- Continuing to provide guidance to Parties to the WHO FCTC, based on COP decisions and

- WHO findings, on countering the activities of the novel and emerging nicotine and tobacco industry;

- Strengthening and expanding the observatories and Knowledge Hubs network and capacity to overcome gaps in the area of novel and emerging nicotine and tobacco products and industry interference;

- Providing clarificatory guides and examples for the Parties in order to capture the behaviour of the tobacco industry in promoting novel emerging nicotine and tobacco products.

- Continuing to support Member States in pursuing different legal options to hold the tobacco industry accountable for the purpose of strengthening tobacco control at the national level.

\footnotetext{
This report is based on the Consultative meeting to address the evolving activities of the tobacco industry in the Eastern Mediterranean Region and response strategies: Article 5.3 - what's next? 12-13 February 2020, Cairo, Egypt (https://applications.emro.who.int/docs/WHOEMTFI205E-eng.pdf?ua=1).
} 


\section{To Member States}

- Coordinating and sharing information between health ministries and existing global initiatives for tobacco industry monitoring;

- Documenting legal, administrative and judicial actions as well as best practices at national level that have advanced tobacco control and relevant policies;

- Building partnership between the public sector and civil society to present a united front for both monitoring and taking of legal, administrative and judicial action against the tobacco industry, and ensure community empowerment and engagement in the process.

\section{References}

1. World Health Organization Regional Office for the Eastern Mediterranean. 66th Session of the WHO Regional Committee for the Eastern Mediterranean, Tehran, 15-18 October 2019 (https://www.who.int/dg/speeches/detail/66th-session-of-the-who-regional-committee-for-the-eastern-mediterranean).

2. World Health Organization Regional Office for the Eastern Mediterranean Region (WHO/EMRO). Consultative meeting to address the evolving activities of the tobacco industry in the Eastern Mediterranean Region and response strategies: Article 5.3 what's next? Cairo: WHO/EMRO; 2020 (https://applications.emro.who.int/docs/WHOEMTFI205E-eng.pdf?ua=1).

3. World Health Organization. WHO Framework Convention on Tobacco Control (FCTC). Geneva: World Health Organization; 2020 (https://www.who.int/fctc/en/). 